\title{
Exploring Applications of Second Generation Archived Transit Data for Estimating Performance Measures and Arterial Travel Speeds
}

Travis B. Glick

Department of Civil and Environmental Engineering

Portland State University

P.O. Box 751

Portland, OR 97207-0751

Phone: (503) 725-4282

Fax: (503) 725-5950

Email: tglick@pdx.edu

Wei Feng

Performance Measurement

Chicago Transit Authority

Chicago, IL 60661

Phone: (312) 681-3486

Email: wfeng@transitchicago.com

Robert L. Bertini

Department of Civil and Environmental Engineering

California Polytechnic State University

1 Grand Avenue

San Luis Obispo, CA 93407-0353

Phone: (805) 756-1365

Fax: (805) 756-6330

Email: rbertini@calpoly.edu

Miguel A. Figliozzi

Department of Civil and Environmental Engineering

Portland State University

P.O. Box 751

Portland, OR 97207-0751

Phone: (503) 725-4282

Fax: (503) 725-5950

Email: figliozzi@pdx.edu

Forthcoming 2015 Transportation Research Record 


\begin{abstract}
Travel time and operating speed influence transit service attractiveness, operating cost, and system efficiency. As part of their bus dispatch system (BDS), the Tri-County Metropolitan Transportation District of Oregon (TriMet) has been archiving automatic vehicle location (AVL) and automatic passenger count (APC) data for all bus trips at the stop level since 1997. In 2013, a new and higher resolution bus AVL data collection system was implemented. This new system provides stop-level data as well as 5-second resolution (5-SR) bus position data between stops. The objective of this paper is to explore potential applications of the new data for assessing transit performance and for estimating transportation system performance measures for urban arterials. Results suggest that the 5-SR data provides high resolution time and position information which can be used to determine bus travel speeds between bus stops, identify speed breakdowns, and estimate intersection signal/queuing delays.
\end{abstract}

Keywords: transit performance; archived data; automatic vehicle location; speed breakdown; urban arterial 


\section{INTRODUCTION}

Analysis and modeling of bus travel time and operating speed are integral for the transportation planning process (1), operations management, route planning and scheduling, and continued performance measurement and evaluation (2). This study uses two sets of archived transit data provided by the TriCounty Metropolitan Transportation District of Oregon (TriMet) via their Bus Dispatch System (BDS): stop-level metrics including automatic passenger count (APC) data and new 5-second resolution data (5SR) automatic vehicle location (AVL) data between stops. The objective of this paper is to explore the new 5-SR data for a particular bus route in Portland, OR and to analyze more detailed bus trip time and speed information that are not visible using previously available, lower resolution AVL and APC data. This paper examines finer resolution bus travel speed as a means to examine speed changes, queuing, and delay at signalized intersections and other locations along route.

The use of buses as probes to estimate travel times has been studied in the past (e.g., 3,4). In particular, TriMet buses have been used as probe vehicles (5) to evaluate arterial and transit performance (6). However, these studies used TriMet stop-level data, which was all that was available at the time. To estimate travel times and trajectories between stops, researchers had to use proxies, such as removing the estimated stop time, which does not account for bus accelerations or decelerations, or estimating travel time using the recorded/reported maximum speed in a segment between stops. Signal delay is also a key source of variability for bus travel time (7) and is of interest to transit operators and researchers.

The route chosen for this study was a 14.8 mile segment that ran from NE Kelly \& 5th to NW 6th $\&$ Flanders in Portland, Oregon. Route 9 is shown in Figure 1. Due to some missing data, the first westbound stop, Gresham Transit Center, was not included in the analysis. Route 9 included 71 westbound trips on 01 May 2013. A total of 22 trips traversed Powell Blvd. between 6:00 a.m. and 10:00 a.m.: fifteen trips began at NE Kelly \& 5th, six trips began at SE Powell and 92nd, and one began at W Powell \& NW Birdsdale. All 22 buses ended their westbound trips at NW 6th and Flanders. Data for all 22 trips were extracted from both the AVL/APC and 5-SR systems.

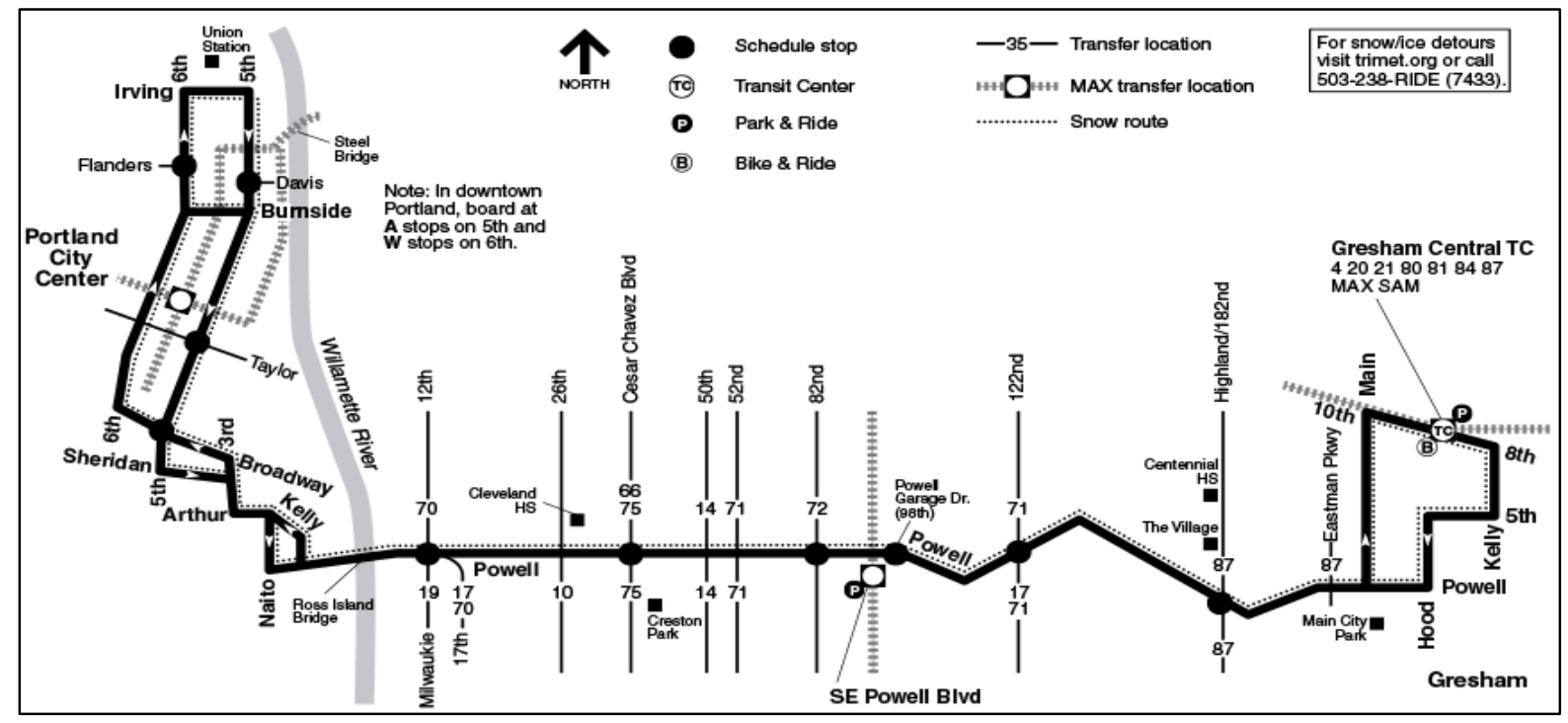

(a) Route 9 schematic (source: TriMet Website) 


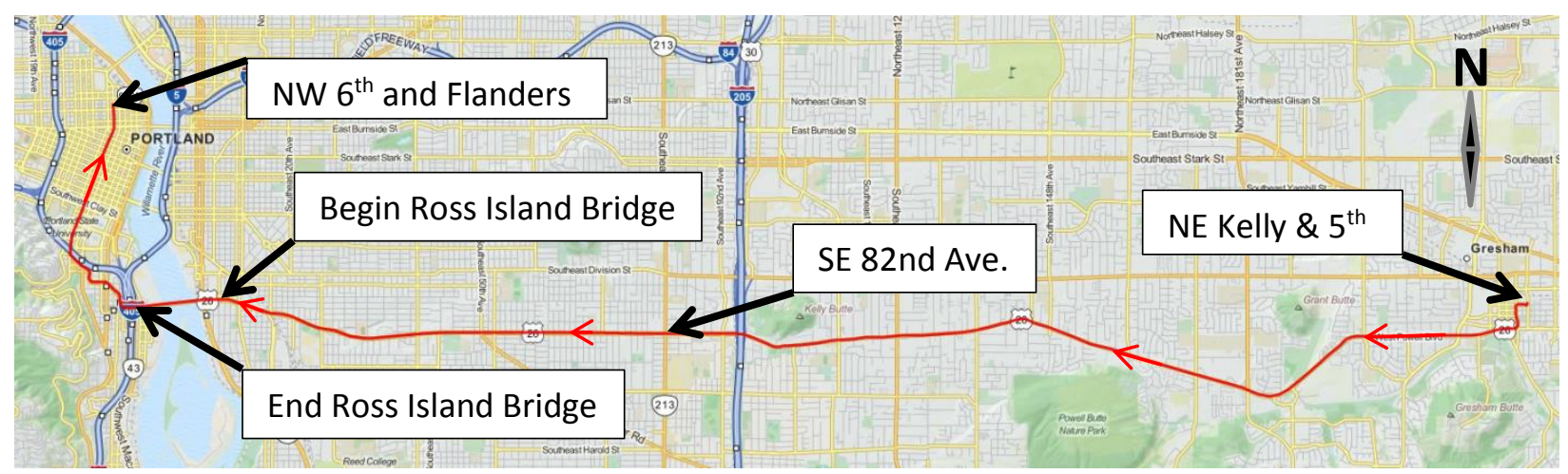

FIGURE 1 TriMet Route 9 overview.

(b) Route 9 (westbound) trip plotted onto Google Maps.

\section{DATA}

TriMet has implemented a Bus Dispatch System (BDS) as a part of its operation and monitoring control system $(8,9,10)$. The BDS post-processes and archives detailed stop-level data from buses during all trips. This includes scheduled departure time, dwell time, actual arrival and departure times, and the number of boarding and alighting passengers at every stop. The BDS also logs data for every stop in the system, whether or not the bus stops to serve passengers. Error! Reference source not found.A contains a sample list of archived BDS data. The calendar date, vehicle, badge, train, trip, and route number are all listed for identification. In the far right column, a location ID number is listed. Each stop location has GPS coordinates associated with it. These coordinates are the basis by which arrival, leave, and dwell time are recorded. Times are not given as shown, but are presented in seconds past midnight, which is then converted into a standard clock format.

Additionally, each location has a predefined 45 foot stop circle surrounding the stop. The "arrive times" and "leave times" are recorded as the time the bus enters and exits the stop circle, respectively. Dwell is recorded when the doors of the bus open. If dwell occurs, arrive time is recorded as the time the doors open; arrive time plus the number of seconds of dwell gives the leave time. Figure 2 shows this setup.

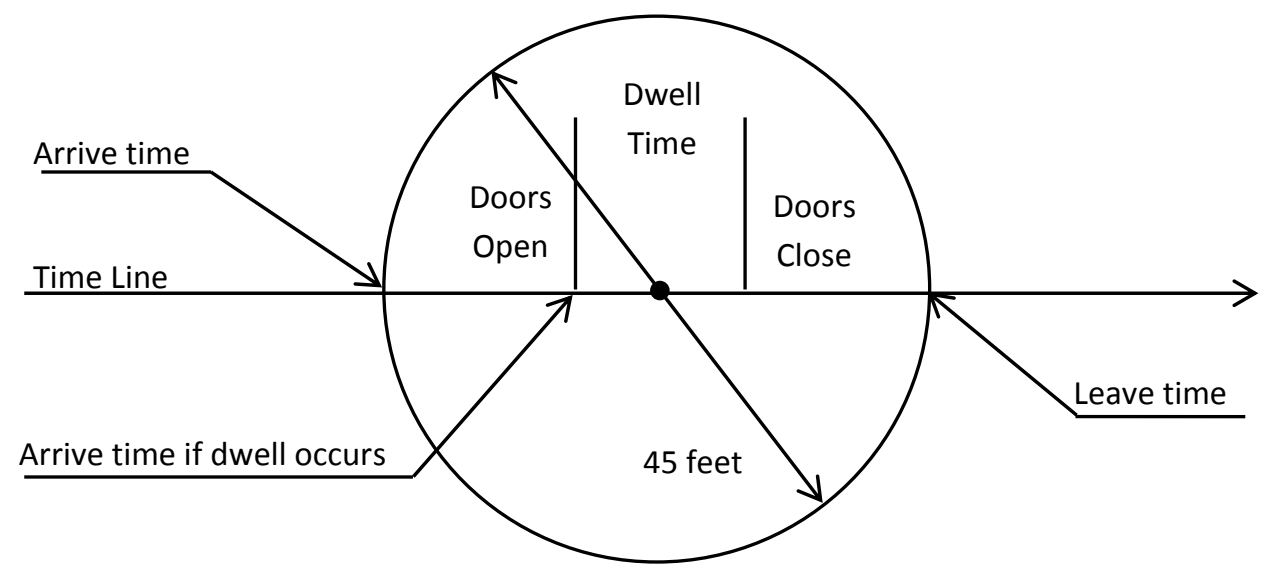

FIGURE 2 BDS Data - Stop circle definition.

When passenger activity occurs, the total number of boarding and alighting passengers is recorded in two separate fields by APCs installed on front and rear door. APCs use infrared light to detect passenger movement and are only activated if the doors open. The use of a lift to assist passengers with disabilities is indicated in the lift field of the BDS data. Additionally, two distance measurements are recorded: pattern distance and train mileage. Pattern distance is an estimate of the linear distance, in feet, from the 
beginning of a route's pattern to the vehicle's current location. Note that scheduled trips for a single vehicle are grouped together into blocks called "trains" for assignment. Train mileage is the cumulative distance, in miles, from the start of the "train's" recorded service (11).

TABLE 1 Sample TriMet Data

a) BDS Data Table

\begin{tabular}{|c|c|c|c|c|c|c|c|c|c|c|c|c|c|c|c|}
\hline $\begin{array}{c}\text { Service } \\
\text { Date } \\
\end{array}$ & $\begin{array}{c}\text { Vehicle } \\
\text { Number }\end{array}$ & Badge & Train & $\begin{array}{c}\text { Trip } \\
\text { Number }\end{array}$ & $\begin{array}{l}\text { Stop } \\
\text { Time }\end{array}$ & $\begin{array}{c}\text { Arrive } \\
\text { Time }\end{array}$ & Dwell & $\begin{array}{c}\text { Leave } \\
\text { Time }\end{array}$ & Door & Lift & Ons & Offs & $\begin{array}{c}\text { Train } \\
\text { Mileage }\end{array}$ & $\begin{array}{c}\text { Pattern } \\
\text { Dist. (ft.) }\end{array}$ & $\begin{array}{c}\text { Location } \\
\text { ID }\end{array}$ \\
\hline 1-Мay-13 & 2260 & 1892 & 934 & 1140 & $6: 54: 30$ & $6: 54: 58$ & 0 & $6: 54: 58$ & 2 & 0 & 3 & 2 & 26.63 & 0 & 3123 \\
\hline 1-May-13 & 2260 & 1892 & 934 & 1140 & $6: 54: 53$ & $6: 55: 32$ & 0 & $6: 55: 32$ & 0 & 0 & 0 & 0 & 26.74 & 568 & 7605 \\
\hline 1-May-13 & 2260 & 1892 & 934 & 1140 & $6: 55: 31$ & $6: 56: 23$ & 10 & $6: 56: 23$ & 0 & 0 & 0 & 0 & 26.92 & 1,496 & 13033 \\
\hline 1-May-13 & 2260 & 1892 & 934 & 1140 & $6: 56: 19$ & $6: 57: 02$ & 0 & $6: 57: 02$ & 0 & 0 & 0 & 0 & 27.12 & 2,671 & 12862 \\
\hline 1-Мay-13 & 2260 & 1892 & 934 & 1140 & $6: 56: 36$ & $6: 57: 12$ & 0 & $6: 57: 12$ & 0 & 0 & 0 & 0 & 27.19 & 3,097 & 9347 \\
\hline 1-May-13 & 2260 & 1892 & 934 & 1140 & $6: 56: 59$ & $6: 57: 28$ & 0 & $6: 57: 28$ & 0 & 0 & 0 & 0 & 27.30 & 3,668 & 4558 \\
\hline 1-May-13 & 2260 & 1892 & 934 & 1140 & 6:58:09 & $6: 58: 31$ & 0 & $6: 58: 31$ & 0 & 0 & 0 & 0 & 27.63 & 5,377 & 12863 \\
\hline 1-May-13 & 2260 & 1892 & 934 & 1140 & $6: 58: 39$ & $6: 58: 49$ & 0 & $6: 58: 49$ & 0 & 0 & 0 & 0 & 27.77 & 6,122 & 4556 \\
\hline 1-May-13 & 2260 & 1892 & 934 & 1140 & 6:59:10 & $6: 59: 20$ & 15 & 6:59:20 & 0 & 0 & 0 & 0 & 27.91 & 6,870 & 4553 \\
\hline 1-Мay-13 & 2260 & 1892 & 934 & 1140 & $6: 59: 49$ & $6: 59: 44$ & 0 & $6: 59: 44$ & 0 & 0 & 0 & 0 & 28.10 & 7,835 & 12864 \\
\hline 1-May-13 & 2260 & 1892 & 934 & 1140 & 7:00:31 & 7:00:09 & 0 & 7:00:09 & 0 & 0 & 0 & 0 & 28.29 & 8,871 & 4516 \\
\hline
\end{tabular}

b) 5-Second Resolution Data with Calculated Values

\begin{tabular}{|c|c|c|c|c|c|c|c|c|}
\hline Vehicle ID & Opd Date & Act Time & *Time & $\begin{array}{c}* \text { Gap } \\
\text { Interval }\end{array}$ & $\begin{array}{c}\text { GPS } \\
\text { Latitude }\end{array}$ & $\begin{array}{c}\text { GPS } \\
\text { Longitude }\end{array}$ & ${ }^{*} \Delta$ Distance & $\begin{array}{c}\text { *Cum. } \\
\text { Distance }\end{array}$ \\
\hline 2205 & 1-Мay-13 & 23334 & $6: 28: 54$ & $0: 00: 05$ & 45.496690 & -122.458707 & 0.0000 & 0.0000 \\
\hline 2205 & 1-May-13 & 23339 & $6: 28: 59$ & 0:00:05 & 45.496295 & -122.459357 & 0.0417 & 0.0417 \\
\hline 2205 & 1-May-13 & 23349 & $6: 29: 09$ & $0: 00: 10$ & 45.495643 & -122.460055 & 0.0563 & 0.0980 \\
\hline 2205 & 1-May-13 & 23419 & $6: 30: 19$ & $0: 01: 10$ & 45.495472 & -122.460537 & 0.0262 & 0.1242 \\
\hline 2205 & 1-Мay-13 & 23424 & $6: 30: 24$ & $0: 00: 05$ & 45.495165 & -122.461137 & 0.0360 & 0.1601 \\
\hline 2205 & 1-May-13 & 23429 & $6: 30: 29$ & $0: 00: 05$ & 45.494790 & -122.461758 & 0.0397 & 0.1998 \\
\hline 2205 & 1-Мay-13 & 23434 & $6: 30: 34$ & $0: 00: 05$ & 45.494400 & -122.462355 & 0.0395 & 0.2394 \\
\hline 2205 & 1-May-13 & 23439 & $6: 30: 39$ & 0:00:05 & 45.494037 & -122.463117 & 0.0446 & 0.2840 \\
\hline 2205 & 1-Мay-13 & 23444 & $6: 30: 44$ & $0: 00: 05$ & 45.493823 & -122.463692 & 0.0315 & 0.3155 \\
\hline 2205 & 1-May-13 & 23464 & $6: 31: 04$ & $0: 00: 20$ & 45.493585 & -122.464338 & 0.0354 & 0.3509 \\
\hline 2205 & 1-Мay-13 & 23469 & $6: 31: 09$ & $0: 00: 05$ & 45.493212 & -122.465003 & 0.0413 & 0.3921 \\
\hline
\end{tabular}

The vehicle identifiers included in the BDS data are not available for the 5-second resolution data, which records a timestamp and GPS location of each bus between stops every 5 seconds if the bus is moving. Using the BDS data as a guide, 5-SR data can be extracted by comparing the times recorded on each. 5-SR data does not start and stop at the beginning and end of a trip; by determining the start and end times for any specific bus and day, that information can be used to define a complete trip of the 5-SR data. Error! Reference source not found.B contains sample 5-SR data and additional calculated values. Columns marked with an asterisk in the table were calculated. When the bus is not moving, data points do not record every 5 seconds and Table $1 \mathrm{~B}$ contains three gap intervals greater than 5 seconds. Hence, the resolution of the 5-SR data is up to 5 seconds.

\section{TRAJECTORY ANALYSIS}

The trajectories of 22 westbound Route 9 buses are plotted in Figure 3 using a time-space diagram, where the slope of each trajectory is the average speed of a bus. The figure shows cumulative distances versus time for all 22 trips between 6:00 a.m. and 10:00 a.m. for Route 9 created using BDS data. The first number in \#\#\#\#_\#\#\#\# is the bus number and the second number is the trip number. 


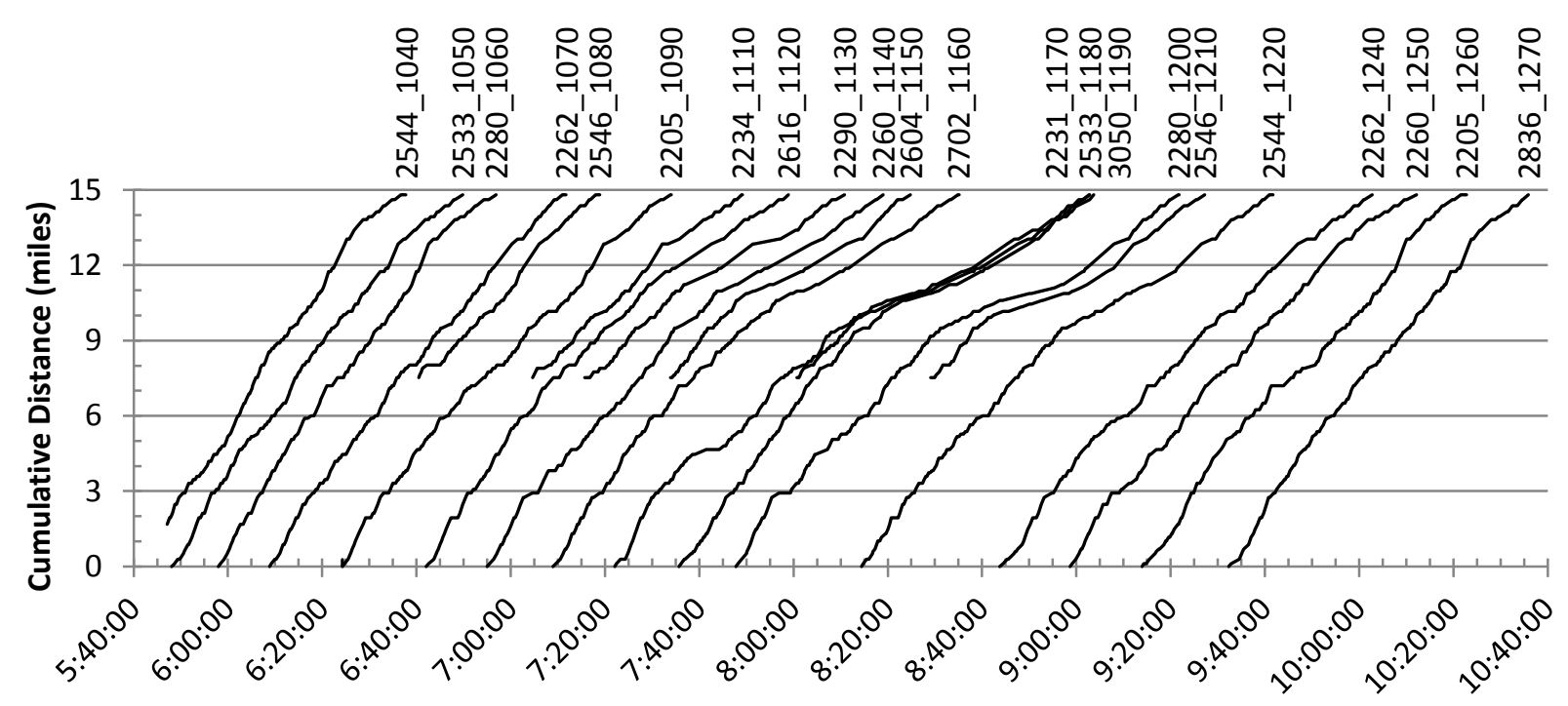

FIGURE 3 Westbound Route 9 time space diagram

Figure 3 shows how the buses' speeds vary over time (scheduled stop times are not shown for clarity). This westbound route carries buses past 84 scheduled stops. On average, the buses stopped at 46 stops but as few as 33 and as many as 54 were serviced by any one bus. Similar trends can be seen across all bus routes. For example, a sudden decrease in average speed is observed just before mile 4 when the buses reach SE 162nd on Powell Blvd; further, a constant average speed is observed at mile 12 when buses begin to travel across the Ross Island Bridge.

Previous research has examined methods for analyzing bus trip time and for producing transit performance measures using archived stop level AVL/APC data for Route 14 in Portland $(12,13)$. Building on this and other previous research in the literature, this paper aims to test and modify/improve the previous methods that relied on the stop level data using the higher resolution bus AVL data now available. To ensure this comparison is justified, bus 2231/trip 1170 was analyzed in depth using both data sets. A time-space diagram (Figure 4A) and an oblique curve (Figure 4B) were created. This comparison highlights the small amount of deviation between the two data sets (14). This result was constant across different buses and trips. Moving forward it can be assumed that the two data sets are close enough to compare directly. Additionally, the similarities between the trajectory analyses implies little benefit to using 5-SR data over stop level data when conducting a trajectory analysis. The previous body of research $(12,13)$ are sufficient to compare differences between scheduled and actual arrive times at stop locations, which are the only locations where scheduled times are available.

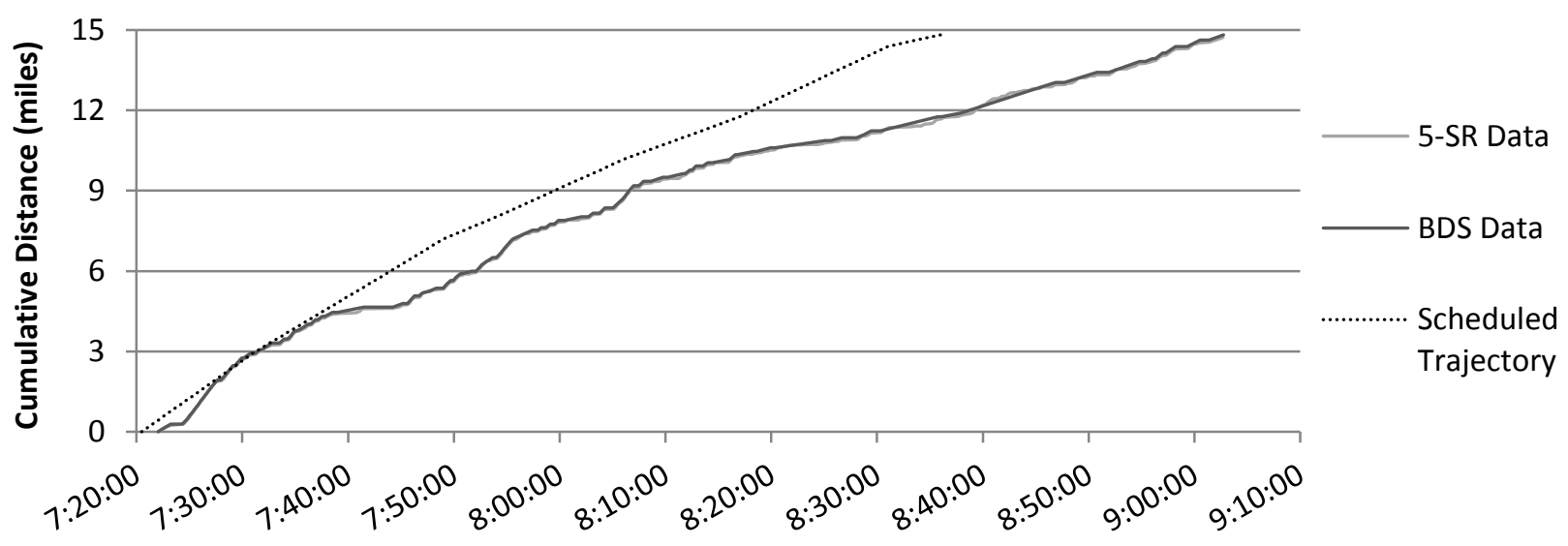

a) Time-space diagram created using BDS and 5-SR data 


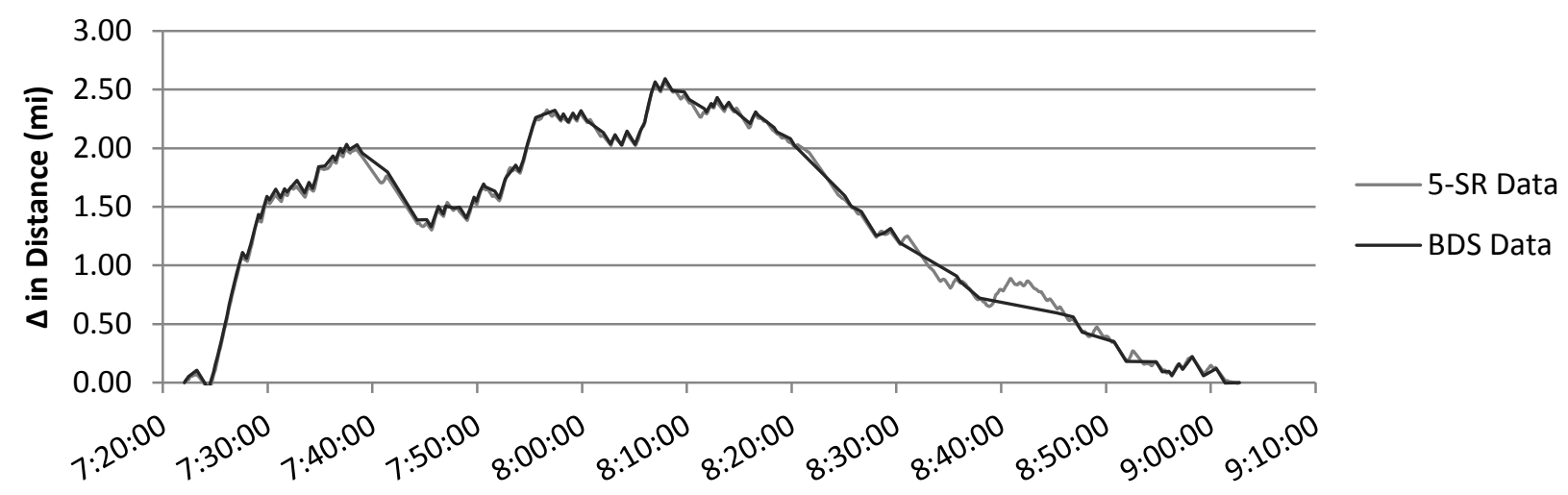

FIGURE 4 Bus 2231 Trip 1170

b) Oblique Curve

\section{CUMULATIVE ANALYSIS}

Global Positioning System (GPS) coordinates can be used to calculate distances between two points. Since GPS coordinates were recorded where $-180^{\circ}<$ longitude $<180^{\circ}$ and $-90^{\circ}<$ latitude $<90^{\circ}$, was used to calculate distances between two points. These differences were then added together for a cumulative distance value. 3959 miles was used as it is the average radius of the Earth.

$\cos ^{-1}\left(\sin \left(\frac{\text { lat }_{1}^{\circ} \cdot \pi}{180^{\circ}}\right) \cdot \sin \left(\frac{\text { lat }_{2}^{\circ} \cdot \pi}{180^{\circ}}\right)+\cos \left(\frac{\text { lat }_{1}^{\circ} \cdot \pi}{180^{\circ}}\right) \cdot \cos \left(\frac{\text { lat }_{2}^{\circ} \cdot \pi}{180^{\circ}}\right) \cdot \cos \left(\frac{\operatorname{long}_{2}^{\circ} \cdot \pi}{180^{\circ}}-\frac{\text { long }_{1}^{\circ} \cdot \pi}{180^{\circ}}\right)\right) * 3959$ miles

When attempting to compare the AVL/APC data to 5-SR positioning data, only the bus number and timestamps can be used to cross reference the data. Once equivalent timestamps have been established, cumulative distance could be calculated for both data sets. The stop level AVL/APC data allows for distance to be calculated three different ways. Train mileage, pattern distance, and stop location GPS data result in average cumulative distances of 14.614 miles, 14.814 miles, and 14.487 miles, respectively for Route 9 westbound. When 5-SR is used, the average cumulative distance is 14.738 miles. It can be assumed that the 5-SR distance calculation is the most accurate estimation of actual bus travel distance; the distance calculated using Google Maps was 14.74 miles. Therefore, the train, pattern, and stop based distance errors are $-0.85 \%, 0.52 \%$, and $-1.7 \%$, respectively. From the AVL/APC data set, pattern distance is most accurate and was used as the cumulative distance to calculate other related metrics on the AVL/APC data.

Dwell time is a directly recorded metric included in the archived AVL/APC data. At each stop, the number of seconds of dwell is recorded, as the time that the door was open. This is not the case with 5-SR data. However, stop time information can still be gleaned from the data. Within this data set, timestamps and GPS are not always recorded every 5-seconds; gaps of greater than 5 seconds are seen when the bus either stops or is moving slowly. Unfortunately, the data does not indicate which of these scenarios initiates gaps in the data recorded since speeds of zero rarely appear in the data. Therefore, the assumption must be made that gaps with calculated speeds of $5 \mathrm{mph}$ indicate a stop. One way to estimate bus stop time is to calculate the change in time between each successive entry to determine the gap time. If the value is 5 seconds or less, no stopping time is indicated. When the change in time is greater than 5 seconds, that time minus 5 seconds indicates the time spent stopped or in slow motion (gap-stop time). The average cumulative gap time indicated by the 5-SR data was 29.5 minutes while the BDS data gave an average dwell time of 20.6 minutes. These two times indicate that the average bus spent almost 9 minutes stopped at locations not associated with passengers boarding or alighting. 


\section{TRIP SPEED ANALYSIS}

While the amount of gap-stop time spent at $0 \mathrm{mph}$ remains unclear, a histogram of bus speed could be created. The speeds of the buses were counted by grouping all reported values into $2 \mathrm{mph}$ bins. The calculated speed was an average over the time period and did not take into account acceleration or deceleration. From the grouping of speed data, it was determined that a majority of the buses' time was spent moving at less than $10 \mathrm{mph}$ with a quarter of that time traveling less than $1 \mathrm{mph}$. Figure 5 shows the breakdown of speeds in $2 \mathrm{mph}$ bins for the average complete trip $(\mathrm{n}=15)$ and for all trips between 6:00 a.m. $-10: 00$ a.m. $(n=22)$. Note that the average trip length was 1 hour 17 minutes.
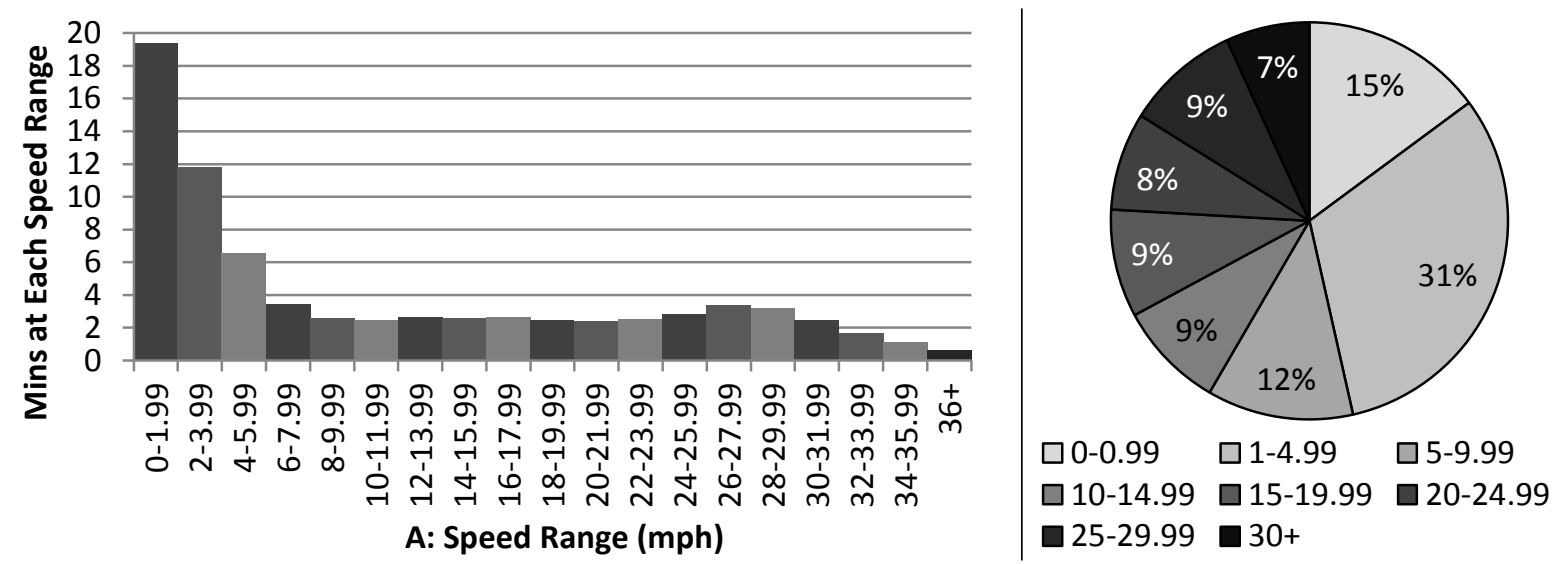

FIGURE 5 Analysis of time spent moving in speed ranges

This analysis reveals a trend for the buses to be moving less than $5 \mathrm{mph}$ for more than $45 \%$ of the time. In order to identify where these low speeds occur along the route, an analysis of trip speed plotted against cumulative distance was conducted. More details about bus travel speeds between stops are not readily available from AVL/APC data as speeds can only be determined between recorded stops. For 5SR data, the average distance between data points was about $1 / 40$ mile (132 ft.) rather than the $910 \mathrm{ft}$. average stop spacing from the AVL/APC system. This $132 \mathrm{ft}$. interval was used to define a cumulative distance and the function needed to create an average.

From data observation, it is clear that in almost all cases there is only one reported speed per bus per interval When a bus speed was reported for a cumulative distance within each $1 / 40$ mile grouping (e.g. [7.900 $\mathrm{mi}-7.925 \mathrm{mi}$ ), [7.925 $\mathrm{mi}-7.950 \mathrm{mi}$ ), etc.), the value was added to a table. If a particular trip did not have a report within the given range, the cell was left blank. When a value was added to the table, a weight for that value was calculated and then also added to the table. The values of the weights are equal to the number of seconds that a speed was maintained within a given cumulative distance interval. For example, if three buses report speeds for the same $1 / 40$ mile segment of $22.5 \mathrm{mph}, 9.0 \mathrm{mph}$, and $1.4 \mathrm{mph}$ maintained for 4 seconds, 10 seconds, and 64 seconds, respectively, a weight of 4, 10, and 64 is assigned to each, respectively. The weighted average speed for that segment would be $3.46 \mathrm{mph}$. Table 2 shows a sample of how average speed was calculated. S1, S2, etc. are speeds for each bus while W1, W2, etc. are weights for those speeds.

While only 6 columns of speeds and 6 columns weights are shown in Table 2, 22 bus trips were used to create Figure 6 which shows the calculated speed versus distance created from both data sets with major intersection locations noted. The solid black line is the weighted average speed created using 5-SR data of 22 trips. The dashed grey line is the average speed created by using the AVL/APC data for the 15 complete trips. The mean number of bus speeds recorded per segment was 14.4 with a standard deviation of 4.6. Figure 6A B, and C show speeds for mile 0 - mile 5.5, mile 5.0 - mile 10.5, and mile 10.0 - end, respectively. 
TABLE 2 Sample of Average Speed Analysis

\begin{tabular}{|c|c|c|c|c|c|c|c|c|c|c|c|c|c|c|c|}
\hline Distance & $\begin{array}{l}\text { Weighted } \\
\text { Avg. Speed }\end{array}$ & $\begin{array}{l}\text { Speed } \\
\text { Count }\end{array}$ & $\begin{array}{l}\text { Weight } \\
\text { Count }\end{array}$ & S1 & S2 & S3 & S4 & S5 & S6 & W1 & W2 & W3 & W4 & W5 & W6 \\
\hline 7.900 & 17.9 & 6 & 30 & 13.5 & 15.1 & 18.2 & 17.3 & 23.0 & 20.5 & 5 & 5 & 5 & 5 & 5 & 5 \\
\hline 7.925 & 4.6 & 6 & 74 & 17.0 & 13.3 & 7.7 & 14.9 & 0.5 & 10.2 & 5 & 5 & 5 & 5 & 49 & 5 \\
\hline 7.950 & 7.0 & 4 & 30 & 13.3 & --- & 13.4 & 1.0 & 12.1 & --- & 5 & --- & 5 & 15 & 5 & --- \\
\hline 7.975 & 2.8 & 5 & 191 & --- & 2.1 & 9.4 & 14.6 & 10.1 & 2.0 & --- & 81 & 5 & 5 & 5 & 95 \\
\hline 8.000 & 3.2 & 4 & 119 & --- & 30.8 & 2.0 & 10.9 & 1.7 & --- & --- & 4 & 45 & 5 & 65 & --- \\
\hline 8.025 & 5.3 & 5 & 139 & 2.5 & --- & 23.5 & 4.0 & 28.0 & 24.8 & 94 & --- & 5 & 30 & 5 & 5 \\
\hline 8.050 & 28.9 & 4 & 20 & 28.1 & 31.5 & 25.9 & --- & --- & 30.2 & 5 & 5 & 5 & --- & --- & 5 \\
\hline 8.075 & 29.1 & 2 & 10 & --- & --- & --- & 29.3 & 28.9 & --- & --- & --- & --- & 5 & 5 & --- \\
\hline 8.100 & 20.4 & 6 & 31 & 30.2 & 12.8 & 13.0 & 30.3 & 27.7 & 9.9 & 5 & 6 & 5 & 5 & 5 & 5 \\
\hline
\end{tabular}

The speed between stops was also calculated from the AVL/APC data by dividing the distance between two successive stops by the difference between arrive time at the second stop and the departure time at the first stop. It should be noted that even though the buses had dwell time where their speed would be $0 \mathrm{mph}$, this was not shown in Figure 6 . The distance between of locations with AVL/APC data creates uncertainty in speeds calculated from that data alone. Due to the higher number of reports at positions between stops locations of AVL/APC, speeds calculated from 5-SR data have a higher resolution and can be used to examine trip characteristics previously obscured by the lower resolution AVL/APC data. The new 5-SR data allows a better detection of congestion or delays at intersections. The analysis also reveals a trend that congestion is prevalent before and after crossing the Ross Island Bridge but traffic still runs smoothly on the bridge itself.
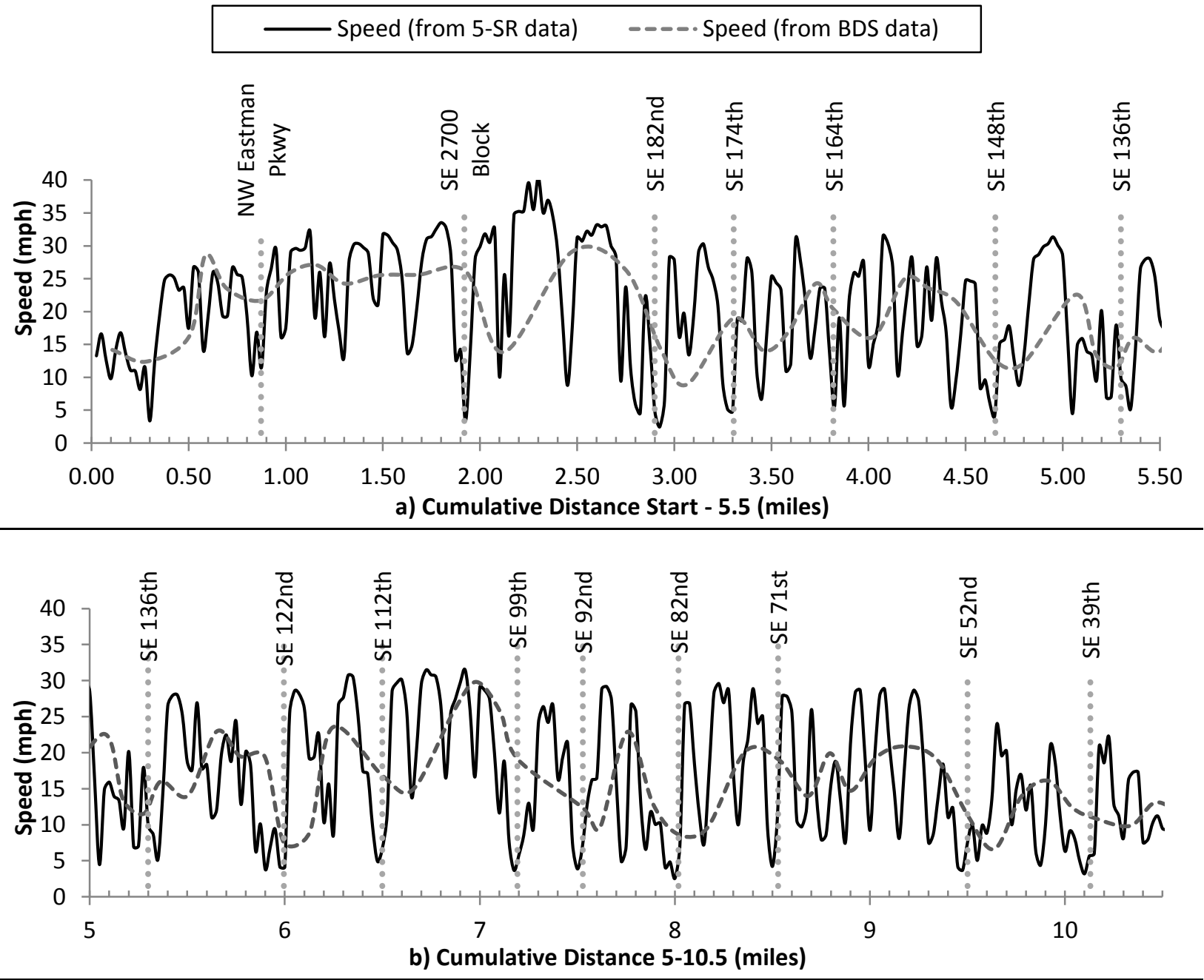


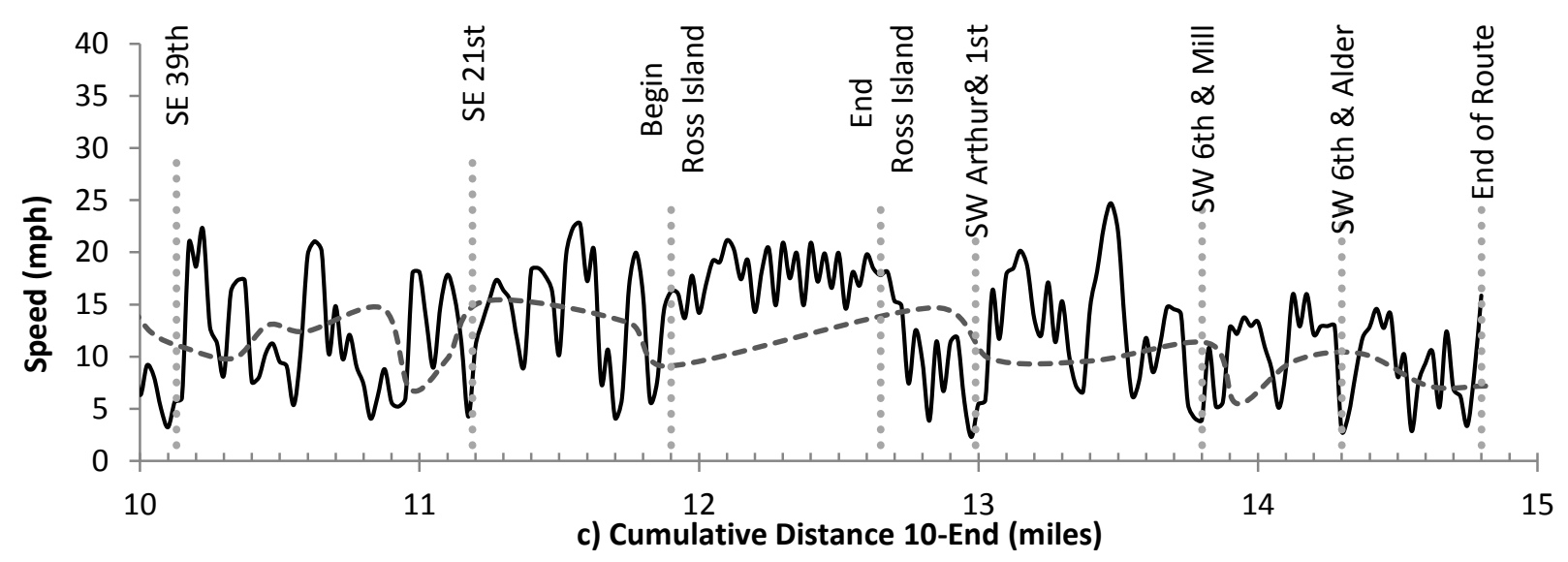

FIGURE 6 Average speed versus cumulative westbound trip distance, $n=22$

The two data series in Figure 6 do not contain all the same information at different resolutions. Since distance is used for the $x$-axis, only non-zero speeds permit the function to continue, the AVL/APC data lacks stop time consideration while the 5-SR plot does not since slow speeds associated with long gap time are taken into account. For example, at distance 7.900 in Table 2, all 6 speeds are similar and have equal weight because each speed was recorded for a 5-second interval while at 8.000 the largest speed has a weight of 0.8 while the slowest speed has a weight of 13 indicating speed duration of 4-seconds and 65 seconds, respectively. Distance 8.000 marks the crossing of SE 82nd on Powell; while all the buses stopped at this location, zero speeds tend not to appear while using 5-SR data. However, it can be assumed that distances where the average speed falls below $5 \mathrm{mph}$ likely included stopped buses even if the exact stop time is unknown.

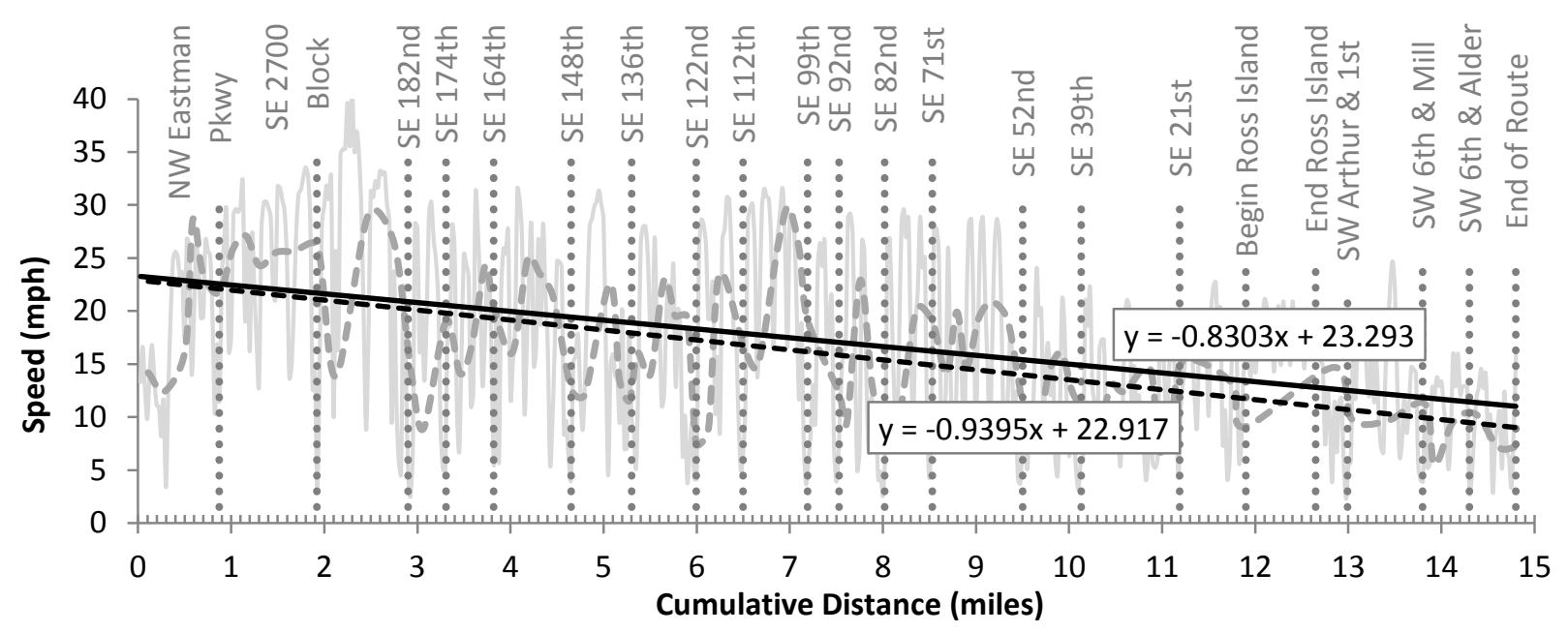

FIGURE 7 Average speed versus cumulative distance trend line, $\mathbf{n = 2 2}$

As shown in Figure 7, the analysis of average speed allowed for two linear trend lines to be created: one for the stop-level AVL/APC data and one for 5-SR. These trend lines indicate that the speed of buses decreases as they move westward during the morning commute. An average speed estimate can be calculated by integrating the linear regression lines over the distance and dividing by total distance traveled. This average speed divided by total distance gives an average trip time estimate. The AVL/APC and 5-SR data sets resulted in calculated average trip times of 1 hour 4.7 minutes and 1 hour 9.5 minutes, respectively. Since it is known that the mean trip time was 1 hour 17 minutes, an error of $>10 \%$ is associated with each estimate. 
Despite this error, the trip speed versus distance graph allows for the locations of unscheduled stops to be observed. For example, the quarter mile running up to mile SE 82nd (mile 8.0) runs slow preceding the stop location. This is likely caused by buses waiting in queues before crossing SE 82nd to reach the stop on its far side.

\section{TRIP TIME ANALYSIS}

Figure 8 was created using similar methodology employed in the creation of Figure 6 . The $x$-axis is the actual time and the $y$-axis represents an average speed created from all bus trips operating over all positions along the route at the same time. The grey line is an average speed at 5 second intervals. The black line is 1-minute moving average speed with \pm 30 seconds of accuracy. The white line is a polynomic trend line that highlights the overall shape of the plot. A dip in the speeds between 7:00 a.m. and 9:00 a.m. coincides with the morning congestion and represents a decrease in average speed of about $9 \mathrm{mph}$.

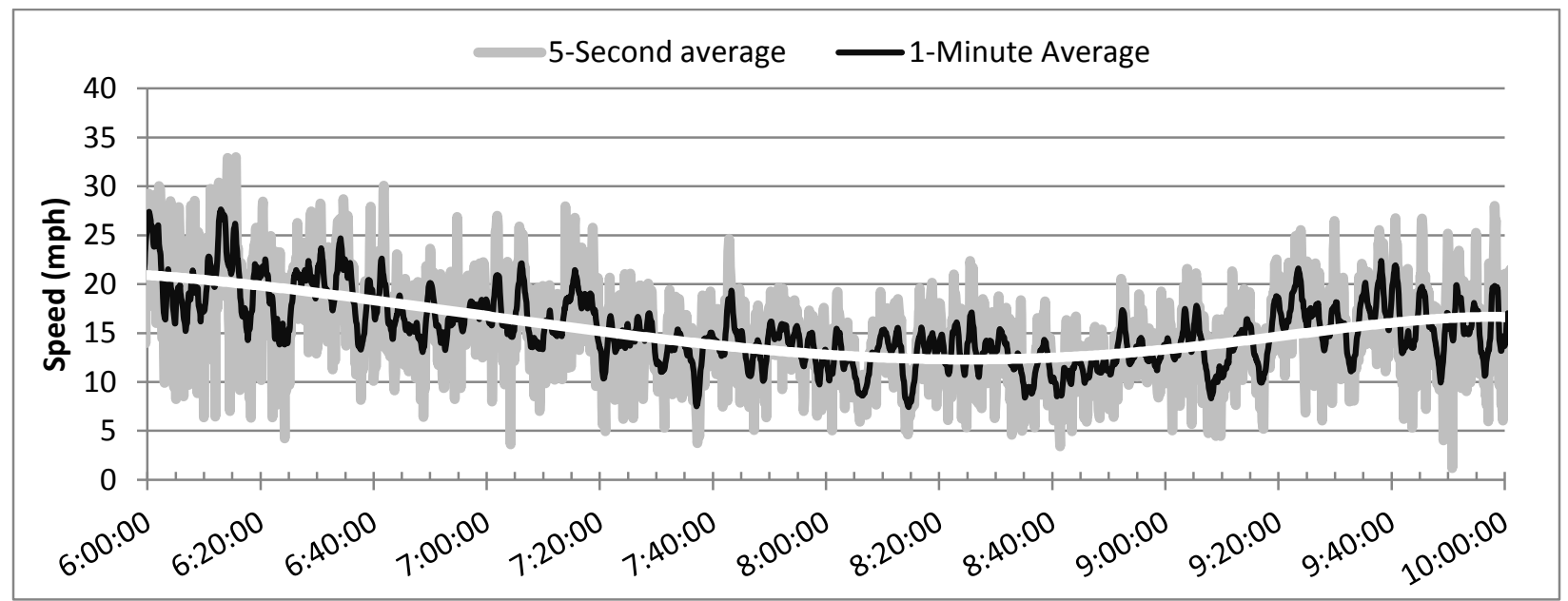

FIGURE 8 Average bus speed versus time, $2 \leq n \leq 6$

A trip time analysis using 5-SR data has some limitations created by the lack of information regarding passenger movement (i.e. passenger boarding and alighting), specified dwell time, use of a lift, traffic signal indications, activation of transit signal priority, etc. Without more independent information, a trip time model using 5-SR data will be of limited utility. The observed decrease in speed serves to confirm the effects of morning congestion on Route 9 buses.

\section{INTERSECTION LEVEL ANALYSIS}

In the previous section, it was noted that around SE 82nd and Powell Blvd., buses have lower speeds; SE 82nd is also Oregon route 213 and has higher traffic signal coordination priority than Powell Blvd. The area from SE 84th - SE 80th was examined in detail and is shown in Figure 9, average bus speed is decreasing as they approach SE 82nd. Bus speed increases after the bus has passed its scheduled stop on the far side of the intersection (most buses stop at 82nd). The speed of the buses is steady around $27 \mathrm{mph}$ until the buses pass SE 80th Ave. and approaches the bus stop at SE 79th Ave. This example shows that it is now possible to zoom in into specific intersections and detect areas with significant queuing. 


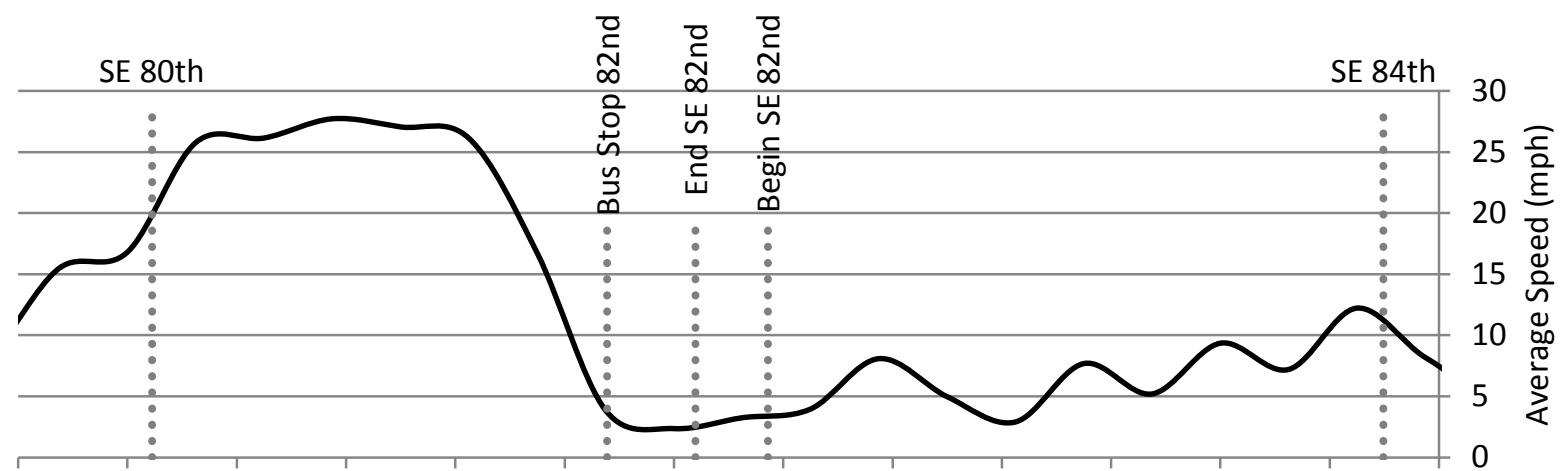

8.12008 .10008 .08008 .06008 .04008 .02008 .00007 .98007 .96007 .94007 .92007 .90007 .88007 .8600

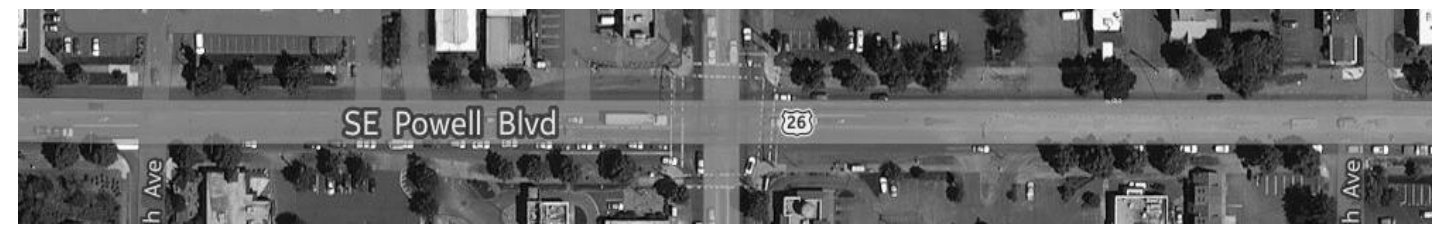

FIGURE 9 Speed Analyses of SE Powell \& 82nd

\section{CONCLUSIONS}

The results of this study suggest that the new generation of higher resolution bus trajectory data can be successfully employed to identify congestion along urban arterials.

The analysis conducted shows that 5-SR data can be used to observe metrics about operating speed in more detail than could previously be seen using stop-level AVL/APC data. This study found that the average travel speed decreased as buses moved eastward on Route 9 with an overall average of $17.1 \mathrm{mph}$. Additionally, while it is to be expected that slow average bus speeds should occur at scheduled bus stops, slow speeds were reported on approaches to many bus stops. This indicates congestion before buses were able to reach their stop destinations, especially for bus stops shortly following signalized intersections such as SE 82nd Ave. and SE 39th Ave. An analysis of average speed created using 5-SR data at each intersection can indicate where buses are stopping and highlight whether those locations are intended to be slow moving or a stop.

Dwell time accounted for $27 \%$ of the average trip time of 1 hour 17 minutes. Gap-stop time accounted for $38 \%$ of this average trip. The speed breakdown shows that $46 \%$ of the time was spent moving $<5 \mathrm{mph}$; therefore, it can be concluded that $27 \%-38 \%$ of the time was spent stopped. However, the exact stop time remains uncertain.

The next step is to validate this model by examining specific intersections for all buses for a complete day. This will help to determine more specifically where problems are occurring and allow for solutions to be presented. This analysis calls for a recommendation for a change in TriMet's 5-SR data. It is recommended that reports should be made every 5 seconds regardless of bus motion. This will allow for accurate stop times and the locations of these stops to be directly analyzed. Currently, only assumption of slow speed can be used and actual stopping time is uncertain. In addition, it should be noted that without a few additional pieces of information, 5-SR data is not accessible on its own. It requires that BDS data be used to compare and extract the data. This could be resolved by including additional fields in the data about train and trip number. Wheel sensor movement data could be another complementary dataset to overcome the limitations in this paper.

\section{ACKNOWLEDGEMENTS}

We would like to express gratitude to Steve Callas of TriMet for graciously providing both data sets used for analysis and to the peer reviewers for their helpful and encouraging comments. 


\section{REFERENCES}

1. Levinson, H. S. 1983. "Analyzing Transit Travel Time Performance.” Transportation Research Record, no. 915.

2. Cambridge Systematics. 1999. Multimodal Transportation: Development of a Performance-Based Planning Process. NCHRP Project No. 8-32(2).

3. Hall, R., and N. Vyas. Buses as a Traffic Probe. Transportation Research Record No. 1731, 2000, pp. 96-103.

4. Chakroborty, P., and S. Kikuchi. Using Bus Travel Time Data to Estimate Travel Times on Urban Corridors. Transportation Research Record No. 1970, 2004, pp. 18-25.

5. Bertini, R. L. and S. Tantiyanugulchai. Transit Buses as Traffic Probes: Empirical Evaluation Using Geo-location Data. Transportation Research Record No. 1870, 2004, pp. 35-45.

6. Berkow. M., Wolfe, M., Monsere, and C.M., Bertini, R. L. and S. Tantiyanugulchai. Using Signal System Data and Buses as Probe Vehicles to Define the Congested Regime on Arterials, In Transportation Research Record: Journal of the Transportation Research Board, No. 1870, TRB, National Research Council, Washington, D.C., 2004, pp. 35-45.

7. Feng, Wei. 2014. "Analyses of Bus Travel Time Reliability and Transit Signal Priority at the StopTo-Stop Segment Level.” Dissertations and Theses, June.

8. Strathman, J. G., K. J. Dueker, T. Kimpel, R. L. Gerhart, K. Turner, P. Taylor, S. Callas, and D. Griffin. 2000. "Service Reliability Impacts of Computer-Aided Dispatching and Automatic Vehicle Location Technology: A TriMet Case Study." Transportation Quarterly 54 (3): 85-102.

9. Strathman, J. G., T. J. Kimpel, K. J. Dueker, R. L. Gerhart, and S. Callas. 2002. "Evaluation of Transit Operations: Data Applications of Tri-Met's Automated Bus Dispatching System." Transportation 29: 321-45.

10. Strathman, James, Kenneth Dueker, Thomas Kimpel, Rick Gerhart, Ken Turner, Pete Taylor, Steve Callas, David Griffin, and Janet Hopper. 1999. "Automated Bus Dispatching, Operations Control, and Service Reliability: Baseline Analysis.” Transportation Research Record 1666 (1): 28-36.

11. Data Resources Derived from BDS Card Data. 2003. Stop Event Data Dictionary.

12. Bertini, R. L., and A. M. El-Geneidy. 2004. "Modeling Transit Trip Time Using Archived Bus Dispatch System Data." Journal of Transportation Engineering 130 (1): 56-67.

13. Bertini, R. L., and A. El-Geneidy. Generating Transit Performance Measures with Archived Data. Transportation Research Record No. 1841, 2003, pp. 109-119.

14. Bertini, R. L., and Li, H. 2011. "Comparison of Algorithms for Systematic Tracking of Patterns of Traffic Congestion on Freeways in Portland, OR." Transportation Research Board. 